\title{
Elderly women's experiences of living with fall risk in a fragile body: a reflective lifeworld approach
}

\author{
Leena Berlin Hallrup RN, MSc, PhD student ${ }^{1}$, Daniel Albertsson MD, $\mathrm{PhD}^{2,3}$, Anita Bengtsson Tops, RN, $\mathrm{PhD}^{1}$, \\ Karin Dahlberg RN, $\mathrm{PhD}^{1}$ and Birgitta Grahn RPT, $\mathrm{PhD}^{2,4}$ \\ ${ }^{1}$ Institution of Caring Sciences and Social Work, Växjö University, ${ }^{2} \mathrm{R} \&$ D Centre, Kronoberg County Council, Växjö, \\ ${ }^{3}$ Department of Public Health and Community Medicine, Division of Primary Health Care, Göteborg University, Göteborg and \\ ${ }^{4}$ Department of Health Sciences, Division of Physiotherapy, Lund University, Lund, Sweden
}

\section{Correspondence \\ Leena Berlin Hallrup \\ Institution of Caring Sciences and Social \\ Work \\ Växjö University \\ Georg Luckligs väg 8 \\ SE-351 95 Växjö, Sweden \\ E-mail: leena.berlin-hallrup@vxu.se}

\begin{abstract}
The purpose of this qualitative study was to explore the lived experience of fall risk from a lifeworld perspective in elderly women with previous fragility fractures. Thirteen elderly women with a high risk of fall and fracture, aged 76-86, living in their own homes in rural areas, were recruited from a voluntary fracture prevention programme. All women had a history of fragility fractures and were interviewed in their homes from spring to autumn 2004. A phenomenological reflective lifeworld approach was chosen to analyse in-depth interview data. The study was conducted within an interdisciplinary research group inspired by dialogical research. Elderly women's life space has been narrowed due to advanced age, physical injury or by efforts to prevent new injuries leading to changes in self-perception. However, the women seek strategies to challenge limitations and insecurity, and strive to retain mobility and daily life routines. The four major constituents of the phenomenon 'elderly women's experiences of fall risk' emerged in this study: a changing body, living with precaution, ambiguous dependency and influence and need for understanding. Employing the women's thoughts and resources in trust-based dialogues with caregivers may strengthen their concord and the prospects to continue an active life. Elderly women seek strategies to challenge limitations and feelings of insecurity, and strive to maintain mobility and daily life routines. A trust-based care respecting the preferences of the women seemed to stimulate behavioural change in maintaining an active life.
\end{abstract}

Keywords: accidental falls, age 75 and older, qualitative research, women

Accepted for publication 28 October 2008

\section{Introduction}

Falls have been comprehensively studied in epidemiology and trauma research (Blake et al. 1988, Campbell et al. 1990, Udén et al. 1999, Jensen et al. 2002, Cameron et al. 2003), and several interventions to prevent falls among elderly people have emerged during recent decades (Gillespie et al. 2003, Skelton \& Todd 2004, Albertsson 2007). Common risk factors for injuries caused by falling are high age ( $>65$ years), female gender, balance problems, cognitive impairment, dementia (Cummings et al. 1995,
Tinetti et al. 1995, Swift 2001,Devroey et al. 2002), lack of physical activity (Jaglal et al. 1993) and functional limitations (Koski et al. 1996). These studies report that falls often occur when several risk factors are combined. Falls precede a hip fracture in over $90 \%$ of all cases (Fuller 2000). Hip fractures occur more often among women (Paganini-Hill et al. 1991). Additional clinical risk factors are advanced age, low body weight, a history of fragility fractures and impaired ability to rise from sitting position (Cummings et al. 1995, Albertsson et al. 2007) and low bone mineral density increase the risk of fracture 
even more (Cummings et al. 1995). Such clinical risk factors can help to identify community-dwelling women who are prone to hip fracture (Albertsson et al. 2007).

A previously experienced fall may lead to pain (Hallström et al. 2000), restricted mobility (Mitchell \& Jones 1996), dependency (Tinetti et al. 1994) and fear of new falls (Ness et al. 2004). Furthermore, the fear of falls may decrease the individual's social activities (Lawrence et al. 1998, Ballinger \& Payne 2002). A fall also generates economic societal costs of medical treatment, especially after a hip fracture (Braithwaite et al. 2003, Skelton \& Todd 2004). Taken together, all these factors can contribute to restricting an individual's everyday life. However, there are shortcomings with regard to systematic studies that focus on elderly women's everyday experiences of living with a risk to fall (Ballinger \& Payne 2002). Thus, there remains a need to explore more thoroughly the individual's lived experience of living with a fall risk and its consequences in everyday life among elderly women. From a healthcare empowerment perspective, elderly women's experiences may provide a broader knowledge and deeper understanding of what living with a fall risk entails.

Therefore, the purpose of this study was to describe the meaning of the lived experience of fall risk in community-dwelling elderly women with previous fracture experience as a result of a fall.

\section{Method}

\section{Informants and design}

The informants were 13 women aged 76-86, living in their own homes in rural areas. The women had a high risk of fall and fracture, due to their gender, high age and a history of fragility fractures (Cummings et al. 1995, Albertsson et al. 2007). All the women had participated in a voluntary hip fracture prevention programme since 2002. The women underwent a heel bone mineral density scanning, and were given the scanning results in a letter together with written fall and fracture preventive advice, such as daily outdoor walks, physical training at home or in group, removal of loose carpets and use of secure footwear at home. Before preventive drugs were prescribed, the participants had a telephone contact with their physician. The informants were selected by purpose sampling to create variation in both number of clinical hip fracture risk factors (Albertsson et al. 2007), walking capacity, mobility change and degree of participation in the fracture prevention programme. Women in wheelchairs, those who only walked indoors or had obvious memory impairment were excluded. Fifteen women were contacted by telephone in 2004 (by D.A.), and 13 of them agreed to participate in interviews by returning a written informed consent document. All women were interviewed (by L.B.H.) in their homes from spring to autumn 2004. All authors participated in the analysis of the interviews and after 13 interviews, all authors agreed that satisfactory saturation of the phenomenon was obtained. The Regional Ethics Committee at Lund University approved the study.

\section{Approach and method}

Understanding elderly women's perspectives of their fall risk and its consequences for their everyday life requires an ability to openly meet their lifeworlds. Therefore, we chose a reflective lifeworld approach (Dahlberg et al. 2001). Life manifests itself in experience, and each lifeworld shows structures or styles which need to be studied so that health service providers understand their (prospective) patients.

One such structure that the lifeworld approach claims is the 'body as lived', which is fundamental for the constitution of the lifeworld and everyday life experiences (Merleau-Ponty 1995). According to Merleau-Ponty, we have access to the world only through our bodies, which serve as anchorages and centres of the world. It is through our bodies that we are in a living connection, a personal and subjective relationship with the world. A person can thus never be understood merely as a biological being. Instead, the lifeworld, according to this approach, is constituted by the lived bodily experience of how we are to the world, and how we relate and interact with the world (Dahlberg et al. 2001). From this point of view, illness and health must be understood as an embodied experience, also regarding elderly women's lifeworlds.

Reflective lifeworld research illustrates the world as experienced prior to any theories devised to explain it (Dahlberg et al. 2001). The lifeworld is to be investigated in its own terms, without reference to any external criteria of 'how it is' (Ashworth 1996).

A principle of matter in all phenomenological approaches is openness towards the phenomenon in focus, and researchers must therefore learn how to 'bridle' their evolving understanding of the phenomenon and its meanings (Dahlberg et al. 2001). Researchers practicing a phenomenological approach must also pay attention to and try to control their prior knowledge about the studied phenomenon, not letting prior understanding overshadow new meanings and the phenomenon's 'otherness' (Gadamer 1995). The aim of 'bridling' attention, experience and understanding is to be as aware as possible of the concrete instance of the phenomenon as it exists and presents itself in the research (Dahlberg et al. 2001). 
This study was conducted within an interdisciplinary research group of five researchers representing a caring/nursing perspective, as well as medical and rehabilitation perspectives. The research was inspired by a dialogue research approach (Halling et al. 2006), which encouraged us to discuss the aim of the study, its questions and methods, as well as the emerging interpretations.

\section{The interview}

To obtain expressions of elderly women's lived experience, phenomenological interviews were conducted (Dahlberg et al. 2001). They focused on the lived experience of living with a risk of falling. All interviews started with the question: 'Can you tell me about an ordinary day of your life?' The purpose of this question was to get a background of the phenomenon. Thereafter, a further question was put that focused on the specific phenomenon under investigation: 'Please, can you give a concrete example how fall risk appears in your daily life?' The answers to this question were followed up by questions such as: 'What do you mean by that?' or 'Please can you tell me more about that situation?' The aim of the follow-up questions was to deepen the information by letting the participant reflect over the phenomenon.

\section{Analysis of data}

The analysis was based on the principles described by Dahlberg et al.2001) aimed at describing the essence and meaning structure of the phenomenon 'elderly women's lived experiences of fall risk'. In addition to its aim of illustrating essential meanings, this type of analysis also emphasises various everyday life experiences in relation to the aim of the study and unique meanings embedded in the descriptions of these experiences.

The characteristics of the phenomenological analysis used are flexibility, openness, pliability and movement between whole-parts-whole. The meaning of the parts is understood in relation to the whole and vice versa. All interviews were read through several times to get a sense of the whole and to get familiar with the data. After that and focusing on the phenomenon under study, the data were broken down into smaller parts, meaning units. The meaning units were close to the original text of the interviews and could consist of statements from participants, and words or phrases that captured the different meanings of the phenomenon. Considering variations of similarities, the parts were then put together into clusters and the meaning units were translated into abstractions according to a more scientific language (Dahlberg et al. 2001). The clusters were then organised into patterns which generated a general structure that is the essence of the phenomenon and its constituents. The essence is the core meaning of the phenomenon, while the constituents particularise the phenomenon as a whole. We also analysed the data in a dialogue within the interdisciplinary research group, and the mutual findings thus come from a nursing, medical and rehabilitation perspective.

In the findings, the essential phenomenological meanings are first described, followed by its four major constituents. These represent different aspects of the phenomenon and put together they comprise the phenomenon as a whole. The results are based on all the interviews, but individual statements illustrate and highlight the interpretations.

\section{Findings}

The life of an elderly woman with a high risk of falling and fracturing herself can change as a consequence of an actual fall. The fall may bring about physical changes and also a change of the woman's self-perception. Elderly women can feel that they have become strangers to their changed bodies and to their ageing lives. However, while their lives can be affected by limited mobility and insecurity with an unpredictable threat of falling and fracturing themselves, they describe a will to challenge this limitation. They seek strategies for reducing their insecurities while they strive to keep up their mobility, which leads them into learning to live more carefully.

This carefulness can involve a reduced 'life space'. They live more isolated lives at home, although in a familiar environment. The carefulness makes it more difficult for the elderly women to create and maintain social relationships, and they become more or less cut off from possibilities of partaking in the wider world. At the same time, there is an ambition to re-conquer mobility and to find new daily habits that are experienced as safer, and to maintain the fullness of daily life. They have the courage to improvise and at the same time challenge themselves to find out where the limit is.

The women accept offers of exercise if these activities are characterised by fun and games, in a trust-based atmosphere and potentially improving their mobility. They can, however, experience an ambiguous dependency of support from other people and technical aids. Support and aid expose the body's weaknesses while also exposing the women's courage to show their vulnerability and weakness to others. On the other hand, a walking aid can be seen as a self-evident prerequisite to maintain and possibly expand daily life mobility.

In encounters with the health service, the women's bodies are in the foreground while their fragile existence may end up in the background. The health service provides recommendations that may lead the women to 
passively take in advice and information, and expose themselves to various investigations. Still, the women can express trust in their individual judgements and then choose their own strategies for their continued care. Sometimes, this care was experienced as sporadic and exclusive. Women getting difficult medical advice complained about a lack of relevant information, and their understanding of the advice on a more profound level was not reached.

\section{A changing body}

A fall often indicates a sudden change of the elderly woman's life.

When I fell for the first time, it wasn't that serious, it was OK, but then came this ... (broke her leg) and it was worse. Now, I do not dare to walk ... at least not outdoors, indoors I am trying to ... (Woman 2)

A changed awareness of the body can be experienced negatively and difficult to understand - almost as alienation to one's own body.

... to have the body that I have. I don't believe much that it'll get any better./ / ... I mean, I can feel the whole ... , that I have it in the whole body. And the same with the hips now, here by the buttocks, it's just like it's changed. (Woman 8)

The changed body is experienced as different. With the perceived fall risk follows insecurities regarding the body's balance and appearance.

... you sort of feel that you no longer have this stability. You feel, you can say you feel unsteady, it becomes an insecurity. (Woman 8)

A changing body also involves future fear. The women get worried about what can happen to them when they loose their mobility. They do not take for granted how their body and life situation will be. Not least is their future fear connected to being forced to move away from home.

... because then we can't live here anymore if anything else would happen. (Woman 7)

\section{Living with precaution}

Living with a changing and an unsteady body entails insecurity that causes the women to develop different strategies for dealing with their daily life. They are forced to live more carefully, which becomes a natural habit. Their own home becomes a central place for developing careful strategies. While their home is perceived as safe and secure, and to some extent predictable, it also limits them, and they are gradually unable to actually leave their home.
I feel more alert if I go out for a while.//I walk, I go up to the road crossing there ... then, I turn and walk a couple of times. But, when it gets slippery I don't go there, then I only walk on this here little path to that little gate. Then, I only walk back and forth here sometimes. (Woman 7)

Moving more carefully is experienced as safer, and mobility can partly be maintained even if carefulness causes a reduction of life space. The women are longing to do things that used to be self-evident, like cycling, walking in the garden and visiting friends and family. Despite an apparently careful life, elderly women sometimes get the courage to look beyond their ageing changing bodies and high fall risk. They then aspire to daily life as it used to be, which sometimes makes them deny their predicament.

... it's nothing I think about every day, that I'm very fragile ... It's just to think I'm going to try to manage on my own and not fall ... I soon will have to give up, that's nothing I go around thinking about ... no, I really don't. (Woman 4)

Despite their reduced mobility and changed body experience, elderly women sometimes defy their frailty. These situations become challenges to the limits of caution they or people close to them have established.

... I think that, I have to be careful so I don't fall ... because my daughter says to me, 'Don't bother climbing your step ladder or this to take something down.' But, I do anyway when I can't reach. (Woman 4)

\section{Ambiguous dependency}

Dependency means that the elderly women have to conform to other people's goodwill, and their own needs might not be taken care of. An exaggerated adaptation to the fall risk and the changing body can thus increase the risk of the women becoming socially isolated in their home. Asking other people for help is obviously not always the right thing. Instead, the women can adjust their habits to changed mobility as a way of maintaining independence.

Socializing with relatives and friends is seen as a central concept in the life of elderly women. Visits are described as highlights in everyday life. Taking walks together can create and maintain networks.

We met in the woods over there ... so, we became good-enough friends to meet almost every day ... and she always pops by and looks after me ... then we go out and take walks together.

Behind the ambiguous dependency of other people, and the difficulty in creating new social relationships while maintaining their current ones, feelings of vulnerability, loneliness and abandonment emerge.

... what would I do if I fell? I am not sure that I can call them (the children), or them over there (the neighbours) ... but it's 
not for certain that they'll ring and care about me. I might end up lying there. (Woman 13)

Ambiguous dependency is also experienced in relation to different technical aids such as a cane, Zimmer Frame or hip protectors, which entail both opportunities and obstacles. On the one hand, the women would not be able to increase their life space without an aid.

... you see, I don't dare to walk without the cane. If I have to go out on the street, out there, to my friend, then I kind of don't trust myself. (Woman 8)

On the other hand, technical aids can hinder the women in social interaction when the need for aid causes embarrassment. The cane is experienced as an external sign of body weakness, as a source of embarrassment in front of other people.

When you walk out there with a cane, I'd rather not show myself. That I am so ill that I can't walk. (Woman 10)

The various technical aids sometimes contribute to frustration in relation to themselves and to efforts regarding aid. It is particularly frustrating when they do not understand the purpose of an aid, when the efforts are seen as too late and when an earlier fall already has caused injury.

... I have hip protectors. They (the health service) want me to have that. But I don't want to. It feels very clumsy. ...//What on earth do I need it for? I should have had it before I fell, now I have no use for it any more. (Woman 2)

\section{Influence and need for understanding}

Some women describe a lack of trust in the body's physical and social function. This may lead to contacts with the health service. The women rely on the carers' knowledge and want trusting and understanding relationships with them. Stable caring relations that confirm the elderly women's situation can lead to increased feeling of safety.

... when you have a doctor, it's nice to see the same one .... It feels safe, yes it does, because he knows exactly what my life is like. (Woman 1)

While the women want this trust in healthcare relations, they do not want sporadic contacts with the health service, especially when they feel that their own body knowledge and situation carry little meaning in the relationship. They feel vulnerable when they cannot establish mutual confidence and trust. Advice and, when required, suggestions for bone-strengthening treatment may be experienced as providing security and an opportunity to maintain their life space.

... there's something wrong with my spine ... when I was getting up ... then I had to crawl to the door, grab the handle and pull myself up ... then I could walk ... so, it has helped with his medicine, calcium and such. (Woman 12)

Elderly women experienced that health service information sometimes was unclear and difficult to accept, questioning statement of low bone mineral density or positive effects of suggested fracture preventive treatments. The information from carers raised questions and personal thoughts, and need for completion and further dialogue.

... I later received a paper about this ... that I had low density.// and that surprised me ... because I remember that when I was young, both my parents and my siblings said that I had such strong bone tissue, they always said that,//... I told her (my daughter) about it, that I was surprised. Yes, but you see mother, it can become worse when you get older, she said. (Woman 9)

The women also use social relationships to obtain knowledge that the health service is unable to provide. When the women's support for understanding their changing body falls short, they become ambivalent towards following prescriptions. They might take the prescribed bone-strengthening medicine, yet doubting its effect.

... has it worked thus far, it'll work a little longer, that's how I think.//... I do it just because I've been prescribed (take the medicine), I don't believe in it, not much//it's probably too late.//... I don't think you can rebuild anything new on an old woman like me, I don't ... and I don't notice any difference since I've taken these pills. I don't understand anything. And I don't know if they're going to check me again. (Woman 4)

Some of the women confirmed taking additional medication to treat body weakness caused by other medication. Other women experienced that a lack of continuity from the doctor led to a non-compliance and mistrust of taking further medication.

... but the doctor that did these investigations on osteoporosis wasn't here for very long.//Then he wasn't here anymore, they (the carers) thought that we'd care about the medication. But, anyway ... I stopped taking it. Because I didn't hear from him (the doctor) again.... You can go around worrying sometimes for doing that. (Woman 9)

The women need understanding and support in their changed situation. They accept offers from the health service to take part in exercise classes if they are enjoyable and playful, or experience an increased mobility. In this new strange context, they may once again dare to challenge the body's abilities when feeling joy and receiving attention.

... it's really good with the exercise classes, ... if they continue with them I will go again. My back is much better, I am more relaxed, to be able to lie there, and turn, was really nice. And 
then I had some trouble getting up, ... so, I needed some help with that in the beginning ... but now, the last time I did it myself ... and that's proof that it's good for me. Yes, that was fun. (Woman 1)

Sometimes though, the exercise classes are not adapted to their needs. The exercise level could be unsuitable or it is too difficult to get to the exercise location. At times, the offered exercises are too easy, while sometimes too demanding. Elderly women rely on their own judgement when deciding on whether to take part in group or individual exercise. If considering group exercise, they would also consider whether they wanted to expose their physical disabilities to others.

... the exercise classes here at Old Oak (nursing home) ... it doesn't quite suit me ... they just sit and move a little like this ..., I want to work more with mine ...//... but, there'll be a day when I'm not able to, maybe, and then I'll do it ...//... these pensioners have a group with ski pole walking. And they told me to join. And then there were people who were not handicapped like me. And they walked like, like there was smoke behind them. And I couldn't do that, with my knees and my back. Therefore, I chose to walk at my pace with the ski poles ... but now I've found my tempo. Somewhere in between. (Woman 4)

\section{Discussion}

All ageing women need to relate to the gradual changes in their bodies, and that different forms of brittleness and vulnerability develop over time. This is most apparent in women with an increased risk of fracture. It is these women's own lived experiences we are focusing on in this study. Earlier research has mainly studied falls and fractures in nursing homes. This study, based on a lifeworld approach, attempts a more in-depth understanding of the life of elderly women living with an increased risk of fracture in ordinary housing.

\section{Main results}

\section{A changing body}

The women had developed strategies to guide themselves and find ways of relating to their changing body and how it communicates its present mobility. According to Mattsson (1998), this is an expression of the phenomenological lived body. The ego/self manifests itself through the body, and by trying to understand what a woman communicates in her body language, we can learn how to strengthen the individual's potential for a continued active life. The women's body awareness, feeling of control and coping ability varied, but they expressed a strong self-focus attempting to accept themselves and their current needs. They looked after themselves and realised their own value in relation to others (Grahn et al. 2001).

\section{Living with precaution}

The women used different individual strategies to find their own balance between mobility and experienced risk of injury, based on their varying physical functions, decreased mobility and long life experience. They expressed a concern about their future mobility and capacity to get on by themselves. The women's stories indicate how their lived bodies were present in every action and movement, and that the unity of body and mind completes every moment of existence. We found great variation between the individuals' capacity to find new solutions, adapted to a changed and occasionally varying mobility. To live carefully with a fragile body requires the capacity to change and adapt to everyday life. Physiological and psychological aspects intertwined as there is no single movement or action in a living body that does not carry aspects of both (Roxendal 1985, Merleau-Ponty 1995, Gyllensten 2001). Additionally, having a strong self-focus is important for motivating a change in one's life situation (Grahn et al. 2001). This illustrates the importance of looking for the individual's own thoughts and resources in the dialogue between patient and carer in the resulting treatment and care work (Ballinger \& Payne 2002).

\section{Ambiguous dependency}

The women showed differences in their courage towards living with a fragile body. This is in line with qualitative research focusing on perceived risk of living with osteoporosis (Reventlow 2007). The women also found great value in social contacts combined with regular physical activities (group exercise, walking, playing bole, dancing). In such situations, they challenged the limits of their physical abilities. How might the health service and the rest of society meet women on this level? The women's experience of using visible aids varied, as sometimes they were regarded as exposing the women's physical handicap and thereby limiting the use and help, while other women saw the aids as natural tools for increasing mobility and the opportunity for social contact. The prescription of aids is a matter of resources, and it is vital that the aids are used (Skelton \& Todd 2004). The result of this study indicates the importance of a close dialogue with the patient about the benefits and drawbacks, as well as how to use the aids, when prescribing them. The current high use of, for example, walking aids among elderly women (Albertsson et al. 2006) suggests a more accepting attitude towards that type of aid.

\section{Influence and need for understanding}

The need for health service support varied, as well as the ability to adapt to a more confined life space. While 
the health service can provide general advice and expert knowledge, it is the women themselves who identify their needs according to the situation (Ballinger \& Payne 2002, Reventlow 2007). Openness and offers of individually adapted exercise have been efficient for other groups of patients (e.g. for those suffering pain) (Gard 2001), as well as for patients with a high risk of fall and fracture (Campbell et al. 1999, Dinan et al. 2006, Albertsson 2007). Investigating the women's life and previous activity level, and what they used to regard as enjoyable activities, can be a successful strategy (Malmgren-Olsson \& Armelius 2001). General efforts from the health service need to be intertwined with the women's own priorities and desired activities (Reventlow 2007). The interactive aspects of treatment should gain more attention as well as a more patient-centred approach, where the patient is seen as an active problem solver and valuable collaborator (Ballinger \& Payne 2002). The women appreciated occasions when the health service was provided for them personally and continuously. This can be seen against the background of the high turnover of staff within the Swedish health service in municipalities and counties (National Board of Health \& Welfare 2005). It is emphasised from the health services that physical activity results in health benefits, and maintains the musculoskeletal system in good shape. The 2005 Public Health Policy Report presented the importance of providing daily exercises for elderly people and for spending time in outdoor daylight. The home help services need to promote these activities in everyday work according to expert views on illness prevention (Swedish National Institute of Public Health 2005).

Worrying about osteoporosis was a prominent feature in the women's stories as compared to worrying about previous fractures or old age, the latter having apparent affects on mobility and everyday life (Cummings et al. 1995). In line with previous research, it was sometimes difficult to accept information about a low bone density based on a technical measurement, and the women's understanding of the term osteoporosis varied (Reventlow 2007). Despite both written and verbal information from physicians, some women lacked information about their osteoporosis and medication. Repeated information and dialogues based on the women's reflections, possibly together with significant others, may improve and deepen the communication process. This could increase the women's understanding of and adaptation to the chosen treatment, especially for those with failing strength and mental functions. The health service needs to attend to the women's needs, which is likely to result in the women themselves complying better with the recommendations of the health service.

\section{Limitations of the study}

The strengths of this study come from the richness of data obtained during in-depth interviews conducted with elderly women. The richness of these interviews with a small group can provide knowledge of general interest in order to understand these women's unique situation. However, the method has its limitations. It puts demands on the interviewer during the collection of data. There is a strong risk of bias if the interviewer is unsuccessful in collecting rich data. An important aspect of interviewing is the interaction between interviewer and interviewee, upon which the quality of the interview depends (Mishler 1986). The greatest disadvantage of the method is the lack of generalizability, and it is difficult to know whether the findings will be manifested in other subjects (Patton 1990). Because this study included only 13 women, there is a limited potential for generalizing the results to apply to larger groups of elderly people with prior falls and fracture. Nevertheless, scientific knowledge of living with fall risk and a fragile body is limited. We are thus inclined to believe that the research presented here may provide a basis for future research and improvements within health care.

\section{Conclusion}

For elderly women with experiences of fractures, the life space has been narrowed due to their advanced age, the physical injury and anticipatory anxieties for a new fall. The fall also results in physical and psychological changes which may alter the woman's perception of herself. The women seek strategies for decrease feelings of insecurity while they strive to maintain mobility and seek a compromise that allows them to carry out their daily routines. A trust-based dialogue between patient and carer, where the individual's own thoughts and resources are employed, seems to strengthen the concord between health care and the woman, and her opportunity to continue an active life.

\section{Acknowledgements}

We thank all of the participants, and R \& D Centre, Kronoberg County Council and Institution of Caring Sciences and Social Work, Växjö University for making necessary resources available and Hans Thulesius, MD, $\mathrm{PhD}$ for revision of the English text.

\section{References}

Albertsson D. (2007) Hip Fracture Prevention by Screening and Intervention of Elderly Women in Primary Health Care. Unpublished PhD Thesis. Göteborg University, Göteborg, Sweden. 
Albertsson D., Gause-Nilsson I., Mellstrom D. \& Eggertsen R. (2006) Risk group for hip fracture in elderly women identified by primary care questionnaire - clinical implications. Upsala Journal of Medical Sciences 111, 179-187.

Albertsson D., Mellström D., Petersson C. \& Eggertsen R. (2007) Validation of 4-item score predicting hip fracture and mortality risk among elderly women. Annals of Family Medicine 5, 48-56.

Ashworth P. (1996) Presuppose nothing! The suspension of assumptions in phenomenological psychological methodology. Journal of Phenomenological Psychology 27, 1-25.

Ballinger C. \& Payne S. (2002) The construction of the risk of falling among and by older people. Ageing \& Society 22,305324.

Blake A., Morgan K., Bendall M., et al. (1988) Falls by elderly people at home: prevalence and associated factors. Age and Ageing 17, 365-372.

Braithwaite R., Col N. \& Wong J. (2003) Estimating hip fracture morbidity, mortality and costs. Journal of the American Geriatrics Society 51, 364-370.

Cameron I., Cumming R., Kurrle S., Quine S., Lockwood K., Salkeld G. \& Finnegan T. (2003) A randomized trial of hip protector use by frail older women living in their own homes. Injury Prevention 9, 138-141.

Campbell A., Borrie M., Spears G.F., Jackson S.L., Brown J.S. \& Fitzgerald J.L. (1990) Circumstances and consequences of falls experienced by a community population 70 years and over during a prospective study. Age and Ageing 19, 136141.

Campbell A., Robertson M., Gardner M., Norton R.N. \& Buchner D.M. (1999) Falls prevention over 2 years: a randomized controlled trial in women 80 years and older. Age and Ageing 28, 513-518.

Cummings S., Nevitt M., Browner W.S., et al. (1995) Risk factors for hip fracture in white women. New England Journal of Medicine 332, 767-774.

Dahlberg K., Drew N. \& Nyström M. (2001) Reflective Lifeworld Research. Studentlitteratur, Lund, Sweden.

Devroey D., Van Casteren V. \& Walckiers D. (2002) The added value of the registration of home accidents in general practice. Scandinavian Journal of Primary Health Care 20, 113118.

Dinan S., Lenihan P., Tenn T. \& Iliffe S. (2006) Is the promotion of physical activity in vulnerable older people feasible and effective in general practice? British Journal of General Practice 56, 791-793.

Fuller G.F. (2000) Falls in the elderly. American Family Physician 61, 2159-2168, 2173-2174.

Gadamer H. (1995) Truth and Method, 2nd revised edn (J. Weinsheimer and D. Marshall, Translators). The Continuum Publishing Company, New York.

Gard G. (2001) Work motivating factors in rehabilitation: a brief review. Physical Therapy Reviews 6, 85-89.

Gillespie L., Gillespie W., Robertson M., Lamb S.E., Cumming R.G. \& Rowe B.H. (2003) Interventions for preventing falls in elderly people. Cochrane Database Systematic Review 4, CD000340.

Grahn B., Stigmar K. \& Ekdahl C. (2001) Motivation for change and personal resources in patients with prolonged musculoskeletal disorders. Journal of Bodywork and Movement Therapies 5, 160-172.

Gyllensten A. (2001) Basic Body Awareness Therapy, Assessment, Treatment and Interaction. Unpublished PhD Thesis. Lund University, Lund, Sweden.
Halling S., McNabb M. \& Rowe J. (2006) Existential-phenomenological psychotherapy in the trenches: a collaborative approach to serving the unserved. Journal of Phenomenological Psychology 37, 171-196.

Hallström I., Elander G. \& Rooke L. (2000) Pain and nutrition experienced by patients with hip fracture. Journal of Clinical Nursing 9, 639-646.

Jaglal S., Kreiger N. \& Darlington G. (1993) Past and recent physical activity and risk of hip fracture. American Journal of Epidemiology 138, 107-118.

Jensen J., Lundin-Olsson L., Nyberg L. \& Gustafson Y. (2002) Falls among frail older people in residential care. Scandinavian Journal of Public Health 30, 54-61.

Koski K., Luukinen H., Laippala P. \& Kivela S.L. (1996) Physiological factors and medications as predictors of injurious falls by elderly people: a prospective population-based study. Age and Ageing 25, 29-38.

Lawrence R., Tennstedt S., Kasten L., Shih J., Howland J. \& Jette A.M. (1998) Intensity and correlates of fear of falling and hurting oneself in the next year. Journal of Aging and Health 10, 267-286.

Malmgren-Olsson E. \& Armelius B. (2001) Physical and psychological health and social relations in patients with prolonged musculoskeletal disorders. Scandinavian Journal of Caring Sciences 15, 181-189.

Mattsson M. (1998) Body Awareness, Applications in Physiotherapy. Unpublished PhD Thesis. Umeå University, Umeå, Sweden.

Merleau-Ponty M. (1995) Phenomenology of Perception (C. Smith, Translator). Routledge, London.

Mishler E. (1986) Research Interviewing: Context and Narrative. Harvard University Press, London.

Mitchell A. \& Jones N. (1996) Striving to prevent falls in an acute care setting - action to enhance quality. Journal of Clinical Nursing 5, 213-222.

National Board of Health \& Welfare (2005) Time for healthcare and social welfare. Report 2005-131-36. [WWW document]. URL http://www.socialstyrelsen.se (in Swedish)

Ness K., Gurney J. \& Wall M. (2004) Screening for risk of falling in community-dwelling elderly people may increase fear of falling. Journal of Geriatric Physical Therapy 27, 100-104.

Paganini-Hill A., Chao A., Ross R.K. \& Henderson B.E. (1991) Exercise and other factors in the prevention of hip fracture: the leisure world study. Epidemiology 2, 1625.

Patton M.Q. (1990) Qualitative Evalutaion and Research Methods, 2nd edn. Sage Publications, Newbury Park, CA.

Reventlow S. (2007) Perceived risk of osteoporosis: restricted physical activities? Qualitative interview study with women in their sixties. Scandinavian Journal of Primary Health Care 25, 160-165.

Roxendal G. (1985) Body Awareness Therapy and the Body Awareness Scale, Treatment and Evaluation in Psychiatric Physiotherapy. Unpublished PhD Thesis. University of Göteborg and Lillhagen Hospital, Göteborg, Sweden.

Skelton D.A. \& Todd C. (2004) Interventions to prevent accidental falls among older people. World Health Organisation Health Evidence Network Document. [WWW document]. URI http:// www.euro.who.int/eprise/main/WHO/Progs/HEN/ Synthesis/20030820_1

Swedish National Institute of Public Health (2005) The 2005 Public Health Policy Report. R 2005: 44. [WWW document]. URL http://www.fhi.se (in Swedish)

Swift C. (2001) Care of older people: falls in late life and their 
consequences - implementing effective services. British Medical Journal 322, 855-858.

Tinetti M.E., Baker D.I., McAvay G., et al. (1994) A multifactorial intervention to reduce the risk of falling among elderly people living in the community. New England Journal of Medicine 331, 821-827.
Tinetti M., Doucette J., Claus E. \& Marottoli R. (1995) Risk factors for serious fall injury among community elderly persons. Journal of the American Geriatrics Society 43, 1214-1221.

Udén G., Ehnfors M. \& Sjöström K. (1999) Use of risk assessment and recording as the main nursing intervention in identifying risk of falls. Journal of Advanced Nursing 29, 145-152. 